\title{
Susceptibilities of Enterococcus faecalis Biofilms to Some Antimicrobial Medications
}

\author{
Kênio C. Lima, DDS, MSc, Luis R. G. Fava, DDS, and José F. Siqueira Jr., DDS, MSc, PhD
}

Enterococcus faecalis has been suggested to be an important etiological agent in endodontic failures. The purpose of this study was to evaluate the effectiveness of chlorhexidine- or antibioticsbased medications in eliminating $E$. faecalis biofilms. One-day and three-day biofilms of $E$. faecalis were induced on cellulose nitrate membrane filters. Each biofilm-containing membrane was thoroughly covered with $1 \mathrm{ml}$ of the test medications and incubated for 1 day at $37^{\circ} \mathrm{C}$. Treated biofilms were then aseptically transferred to vials containing a neutralizing agent in saline solution and vortexed. Suspensions were 10-fold diluted, seeded onto Mitis salivarius agar plates, and the colonyforming units counted after $48 \mathrm{~h}$ of incubation. There were significant differences between the formulations tested. The association of clindamycin with metronidazole significantly reduced the number of cells in 1-day biofilms. However of all medications tested, only $2 \%$ chlorhexidine-containing medications were able to thoroughly eliminate most of both 1-day and 3-day $E$. faecalis biofilms.

Enterococci are involved in a wide variety of infections in humans, including infections in the urinary tract, bloodstream, endocardium, abdomen, biliary tract, burn wounds, and indwelling foreign devices (such as intravascular catheters). They have also become established as a nosocomial pathogen $(1,2)$.

Although enterococci are not normally present or are present in very low numbers in untreated root canals $(3,4)$, they have been suggested to be important agents in endodontic failure. Molander et al. (5) examined the microbiological status of root filled teeth with periradicular lesions and found enterococci in $32 \%$ of the investigated teeth. Under similar conditions Möller (6) and Sundqvist et al. (7) isolated Enterococcus faecalis from $29 \%$ and $38 \%$ of canals that had recoverable microorganisms, respectively.

It has been reported that infections by enterococci can be difficult to treat $(8,9)$. Enterococci show intrinsic and acquired resistances to several antibiotics. They are intrinsically resistant to practically all available cephalosporins and have reduced sensitivity to penicillins, carbapenems and other $\beta$-lactams. Enterococci are also unsusceptible to aminoglycosides. In addition to intrinsic resistances enterococci have acquired genetic determinants that confer resistance to all classes of antimicrobials, including chloramphenicol, tetracyclines, macrolides, and clindamycin $(1,8)$.

Studies have also revealed that calcium hydroxide dressing is ineffective against enterococci $(3,10-12)$. Therefore it seems that the frequent isolation of enterococci in failed endodontic cases puts in question the routine use of calcium hydroxide as an intracanal medication (5).

Recognizing the potential role of E. faecalis in the failure of root canal therapy makes it important to develop strategies to control infections caused by this organism. Thus the purpose of this study was to evaluate the effectiveness of alternative medications in eliminating $E$. faecalis biofilms.

\section{MATERIALS AND METHODS}

\section{Biofilm Formation}

Biofilms of $E$. faecalis strain ATCC 29212 were induced on cellulose nitrate membrane filters. An aliquot of $20 \mu \mathrm{l}$ of an overnight culture of $E$. faecalis grown in brain heart infusion broth (Difco, Detroit, MI) was seeded onto $13.0 \mathrm{~mm}$ diameter cellulose nitrate membrane filters $(0.22 \mu \mathrm{m}$ pore diameter; Whatman Ltd., Maidstone, Kent, UK), which were on the surfaces of Mitis salivarius agar (Difco) plates. Inoculum was standardized to 0.08 to 0.10 at $625 \mathrm{~nm}$ of wavelength. Nine membranes were used for each plate. Plates containing membranes were then incubated for either 1 day or 3 days at $37^{\circ} \mathrm{C}$ in an aerobic atmosphere. The method used herein was modified from that described by Thrower et al. (13).

\section{Antimicrobial Medications Tested}

The medications tested were in gel form. They were as follows: a. $2 \%$ gluconate chlorhexidine, $2 \%$ natrozole, in distilled water

b. $2 \%$ gluconate chlorhexidine, $1.25 \%$ lauryl-diethylene-glycol-ether-sodium sulfate, $2 \%$ natrozole, in distilled water

c. $2 \%$ clindamycin, $2 \%$ natrozole, in distilled water

d. $2 \%$ clindamycin, $1.25 \%$ lauryl-diethylene-glycol-ether-sodium sulfate, $2 \%$ natrozole, in distilled water

e. $2 \%$ gluconate chlorhexidine, $15 \%$ zinc oxide, $1.25 \%$ lauryldiethylene-glycol-ether-sodium sulfate, $2 \%$ natrozole, in distilled water 
TABLE 1. No. of viable bacterial cells in 1-day E. faecalis biofilms after exposure to the test medications (in log units)

\begin{tabular}{|c|c|c|c|c|c|c|c|c|}
\hline \multirow{2}{*}{$\begin{array}{l}\text { Specimen } \\
\quad(n=6)\end{array}$} & \multirow{2}{*}{$\begin{array}{l}\text { Adhered } \\
\text { Cells }\end{array}$} & \multicolumn{6}{|c|}{ Medications $†$} & \multirow{2}{*}{ Control } \\
\hline & & a & b & c & d & e & $f$ & \\
\hline 1 & 7.74 & 2.84 & 0 & 7.47 & 6.14 & 0 & 6.53 & 6.19 \\
\hline 2 & 8.53 & 2.69 & 0 & 7.99 & 6.93 & 1.77 & 7.33 & 6.98 \\
\hline 3 & 6.60 & 0 & 1.30 & 7.33 & 6.89 & 0 & 5.47 & 6.99 \\
\hline 4 & 6.68 & 0 & 0 & 8.50 & 7.10 & 1.23 & 4.78 & 8.24 \\
\hline 5 & 7.00 & 0 & 0 & 8.31 & 6.23 & 0 & 6.75 & 6.84 \\
\hline 6 & 6.17 & 0 & 0 & 8.49 & 6.53 & 0 & 6.47 & 7.34 \\
\hline Mean $\pm S D$ & $7.12 \pm 0.87$ & $0.92 \pm 1.43$ & $0.22 \pm 0.53$ & $8.02 \pm 0.51$ & $6.64 \pm 0.40$ & $0.50 \pm 0.79$ & $6.22 \pm 0.93$ & $7.10 \pm 0.68$ \\
\hline
\end{tabular}

- No. of adhered cells in biofilms after the time of medication exposure.

t Medications in gel form (natrozole): (a) $2 \%$ chlorhexidine; (b) $2 \%$ chlorhexidine and detergent; (c) $2 \%$ clindamycin; (d) $2 \%$ clindamycin and detergent; (e) $2 \%$ chlorhexidine, $15 \%$ zinc oxide, and detergent; (f) $2 \%$ clindamycin, $10 \%$ metronidazole, and detergent; and (control) detergent.

f. $2 \%$ clindamycin, $10 \%$ metronidazole, $1.25 \%$ lauryl-diethylene-glycol-ether-sodium sulfate, $2 \%$ natrozole, in distilled water.

The control group consisted of a gel compound containing $2 \%$ natrozole and $1.25 \%$ lauryl-diethylene-glycol-ether-sodium sulfate in distilled water.

\section{Biofilm Susceptibility Assay}

Each biofilm-containing membrane was thoroughly covered with $1 \mathrm{ml}$ of the test medications and incubated for 1 day at $37^{\circ} \mathrm{C}$. Uncovered biofilm membranes served as a control of adhered and lost cells before and after the application of test medications. Six biofilm membranes were used for each group, including the controls.

At the day of medication application control membranes containing untreated biofilms were transferred to vials containing 10 $\mathrm{ml}$ of sterile saline solution and maintained immersed for $1 \mathrm{~min}$ under light agitation to recover microorganisms not adhered. Afterward each membrane was transferred to another vial containing $10 \mathrm{ml}$ of saline solution and vigorously vortexed for $1 \mathrm{~min}$ to suspend adhered cells. The same procedure was performed for other control membranes after 1 day, which corresponded to the time of medication application. The obtained suspensions were 10 -fold diluted in $0.85 \%$ saline solution and the viable cells were counted on Mitis salivarius agar after aerobic incubation for $48 \mathrm{~h}$ at $37^{\circ} \mathrm{C}$.

Treated biofilms were then aseptically transferred to vials containing $10 \mathrm{ml}$ of saline solution with Letheen broth (neutralizing broth) and vortexed for $1 \mathrm{~min}$. Suspensions were 10 -fold diluted, seeded onto Mitis salivarius agar plates and the colony-forming units (CFU) counted after $48 \mathrm{~h}$ of aerobic incubation at $37^{\circ} \mathrm{C}$.

The same procedures were performed for 1-day and 3-day biofilms. However only medications $a, b$, and e were tested against the 3-day biofilms.

\section{Statistical Analysis}

To confer homoscedasticity to the populations, data concerning CFU counts were transformed in log numbers. Student's $t$ test was used to compare data obtained from untreated biofilms (control group) taken at the day of medication application and after one more day, as well as the number of adhered and lost cells in each period. Data concerning medication effectiveness against biofilms were analyzed for differences using ANOVA and Tukey's test. The significance level was always established in $5 \%(\mathrm{p}<0.05)$.

\section{RESULTS}

\section{Controls}

No significant difference was observed between the mean numbers of adhered and lost cells in 1-day biofilms that were 7.28 and 7.38 (in log units), respectively. Conversely there was a significant loss of cells in 3-day biofilms. The mean numbers of adhered and lost cells in 3-day biofilms were 7.41 and 8.13 , respectively.

After an additional day (corresponding to the time of medication exposure) untreated 1-day.biofilms (control) showed no differences between adhered and lost cell numbers (7.12 and 8 log units, respectively). Again a significant loss of cells was observed for the 3-day biofilms (adhered cells $=6.47$ and lost cells $=8.11$ ).

No differences were found when comparing the number of adhered cells in control 1-day biofilms immediately before the time of medication application (7.28 CFU) and after one more day (7.12 $\mathrm{CFU}$ ). The same results were observed when comparing the number of lost cells before and after the time of medication exposure ( 7.38 and 8 , respectively).

Regarding the controls of 3-day biofilms, the number of adhered cells before medication application was significantly higher when compared with the number of adhered cells after the time corresponding to medication application ( 7.41 and 6.47 , respectively). However no difference was observed regarding the number of detached cells (before $=8.13$ and after medication application $=$ 8.11).

Significant differences were also observed when comparing the number of adhered cells in 1-day and 3-day biofilms after the time corresponding to medication application.

Biofilms that were in contact with the control medication (natrozole plus lauryl-diethylene-glycol-ether-sodium sulfate) showed no significant cell loss (7.10 CFU) when compared with the number of adhered cells in the 1-day biofilm (7.12 CFU).

\section{Susceptibilities of 1- and 3-Day Biofilms}

Results of the effects of the test medications on the 1-day biofilms are shown in Table 1. There were significant differences between the medications tested. Medications $a, b, e$, and $f$ significantly reduced the number of viable bacterial cells in the biofilms. However only the chlorhexidine-containing medications ( $a, b$, and e) were able to completely eliminate most of the biofilms. Medication $d$ and the control medication did not significantly affect the biofilm. Medication $c$ allowed the overgrowth of bacteria.

When comparing the test formulations, it was verified that pairs $a / e, b / e, d / f$, and $d / c o n t r o l$ medication showed no differences re- 
TABLE 2. No. of viable bacterial cells in 3-day E. faecalis biofilms after exposure to $2 \%$ chlorhexidine-containing medications (in log units)

\begin{tabular}{lcccc}
\hline \multirow{2}{*}{$\begin{array}{c}\text { Specimens } \\
(n=6)\end{array}$} & Adhered Cells* & \multicolumn{4}{c}{ Medications $\dagger$} \\
\cline { 3 - 5 } & & $\mathrm{a}$ & $\mathrm{b}$ & $\mathrm{e}$ \\
\hline 1 & 5.3 & 0 & 0 & 1.84 \\
2 & 5.3 & 0 & 2 & 4.72 \\
3 & 6.77 & 0 & 4.1 & 0 \\
4 & 6.77 & 0 & 0 & 0 \\
5 & 7.34 & 0 & 1.84 & 0 \\
6 & 7.34 & 0 & 1.3 & 0 \\
Mean \pm SD & $6.47 \pm 0.94$ & $0 \pm 0$ & $1.54 \pm 1.53$ & $1.09 \pm 1.92$ \\
\hline
\end{tabular}

- No. of adhered cells in biofilms after the time of medication exposure.

† Medications in gel form (natrozole): (a) $2 \%$ chlorhexidine; (b) $2 \%$ chiorhexidine and detergent; and (e) $2 \%$ chlorhexidine, $15 \%$ zinc oxide, and detergent.

garding antibacterial activity. Significant differences were observed when comparing the other pairs.

Because of the results of 1-day biofilms, only medications $a, b$, and e were tested against 3-day biofilms. Results are shown in Table 2. All medications were effective in eliminating or at least inducing a significant reduction of the bacterial cell number in the biofilms. There were no significant differences between medications $(p>0.05)$.

\section{DISCUSSION}

Enterococci are normal commensals adapted to the nutrientenriched, oxygen-depleted, ecologically complex environments of the oral cavity, gastrointestinal tract, and vaginal vault. During tissue invasion enterococci usually encounter adverse environmental conditions, including limited nutrients availability and host defense molecules and cells. To cause an infection enterococci likely express genes favoring survival under these adverse tissue conditions (2).

Definite and potential virulence factors for $E$. faecalis include cytolysin (lytic toward selected mammalian cells), aggregation substance (involved in binding to host cells), pheromones (chemoattractant for neutrophils), lipoteichoic acid (stimulates cytokine production by monocytes), and lytic enzymes, such as protease (gelatinase) and hyaluronidase (2). The cell arrangement in biofilms may also be important in the infectivity of this microorganism.

E. faecalis has been recovered from several oral sites (14). It was selected for use in this study because it exhibits a high level of resistance to a wide range of antimicrobial agents $(1,8,15)$, and it is among the few facultative bacteria associated with persistent apical periodontitis $(5-7,9,16)$. Endodontic infections with $E$. faecalis usually constitute a problem in treatment because this microorganism is difficult to eliminate (9).

The method used herein was useful to induce in vitro biofilm formation. No difference was observed between adhered and lost cells when examining 1-day biofilms. The same finding was verified after one more day of incubation, which simulated the exposure time of the medications tested. These findings indicated that 1-day $E$. faecalis biofilms may be effectively used to compare the antimicrobial effectiveness of medications. On the other hand 3-day biofilms showed significantly more lost bacterial cells than adhered cells. The same finding was observed after one more day of incubation. The number of adhered cells before medication application was also significantly higher than after one more day of incubation. Our findings suggested that 3-day biofilms can be difficult to use in evaluating antimicrobial activity of medications once the number of lost cells is relatively high. However although 3-day biofilms show a smaller number of adhered cells when compared with 1-day biofilms, they are usually more mature and theoretically more difficult to eliminate, justifying their use in the present investigation.

The association of clindamycin with metronidazole significantly reduced the number of cells in 1-day biofilms. However of all medications tested, only chlorhexidine-containing formulations were able to thoroughly eliminate both 1-day and 3-day $E$. faecalis biofilms. Chlorhexidine is used worldwide in dental plaque control and recently has been suggested as an intracanal medication. Although the occurrence of chlorhexidine-resistant enteric strains has been reported (15), the findings of the present study are in agreement with others when evaluating the effects of chlorhexidine against enterococci $(17,18)$.

Studies have revealed that chlorhexidine has significant antibacterial activities against most of the bacterial species isolated from infected root canals $(18-20)$. Chlorhexidine is a cationic molecule that exerts its antibacterial effects by disrupting the integrity of the bacterial cytoplasmic membrane, causing leakage of intracellular contents (18). In higher concentrations the precipitation of the bacterial cytoplasm occurs as result of the interaction between chlorhexidine and phosphated entities, such as adenosine triphosphate and nucleic acids (18).

The medications tested were in gel form (natrozole) to make application in the root canal system easier. In addition they may possibly be retained in the root canal for longer periods. Because the anionic detergent used in some formulations (lauryl-diethylene-glycol-ether-sodium sulfate) has a low surface tension, it could theoretically enhance the effectiveness of the medications on the biofilms. On the other hand an anionic detergent can theoretically dampen the antimicrobial effects of chlorhexidine, which is a cationic substance. In any event our findings demonstrated that this detergent did not significantly affect the effectiveness of the medications (particularly chlorhexidine) on $E$. faecalis biofilms.

The results of this study indicated that chlorhexidine may exert an important role in the eradication of endodontic infection associated with teeth that were refractory to the conventional endodontic therapy. Further clinical studies may help to confirm our findings.

Dr. Lima is assistant professor, Department of Preventive and Social Dentistry, Faculty of Dentistry, Federal University of Rio Grande do Norte, Natal, Brazil. Dr. Fava is currently practicing in São Paulo, Brazil. Dr. Siqueira is professor and chairman, Department of Endodontics, Estácio de Sá University, Rio de Janeiro, Brazil. Address requests for reprints to Dr. José F. Siqueira Jr., R. Herotides de Oliveira 61/601, Icaraí, Niterói, RJ, Brazil 24230230.

\section{References}

1. Morrison D, Woodford N, Cookson B. Enterococci as emerging pathogens of humans. J Appl Microbiol 1997;83:89S-99S.

2. Jett BD, Huycke MM, Gilmore MS. Virulence of enterococci. Clin Microbiol Rev 1994;7:462-78.

3. Byström A, Claesson R, Sundqvist G. The antibacterial effect of camphorated paramonochlorophenol, camphorated phenol and calcium hydroxide in the treatment of infected root canals. Endod Dent Traumatol 1985;1: 170-5.

4. Siqueira JF Jr, Róças IN, Souto R, Uzeda M, Colombo AP. Checkerboard DNA-DNA hybridization analysis of endodontic infections. Oral Surg 2000;89:744-8.

5. Molander A, Reit C, Dahlén G, Kvist T. Microbiological status of rootfilled teeth with apical periodontitis. Int Endod J 1998;31:1-7. 
6. Möller AJR. Microbial examination of root canals and periapical tissues of human teeth. Odontol Tidskrift 1966;74(suppl):1-380.

7. Sundqvist G, Figdor D, Persson S, Sjögren U. Microbiologic analysis of teeth with failed endodontic treatment and the outcome of conservative retreatment. Oral Surg 1998;85:86-93.

8. Heath $\mathrm{CH}$, Blackmore TK, Gordon DL. Emerging resistance in Enterococcus spp. Med J Austr 1996;164:116-20.

9. Engström B. The significance of enterococci in root canal treatment. Odont Revy 1964;15:87-106.

10. Stevens RH, Grossman LI. Evaluation of the antimicrobial potential of calcium hydroxide as an intracanal medicament. J Endodon 1983;9:372-4.

11. Haapasalo M, Orstavik D. In vitro infection and disinfection of dentinal tubules. J Dent Res 1987;66:1375-9.

12. Siqueira JF, Jr., Uzeda M. Disinfection by calcium hydroxide pastes of dentinal tubules infected with two obligate and one facultative anaerobic bacteria. J Endodon 1996;22:674-6.

13. Thrower $Y$, Pinney RJ, Wilson M. Susceptibilities of Actinobacillus actinomycetemcomitans biofilms to oral antiseptics. J Med Microbiol 1997; $46: 425-9$.
14. Rams TE, Feik D, Young V, Hammond BF, Slots J. Enterococci in human periodontitis. Oral Microbiol Immunol 1992;7:249-52.

15. Slots J, Rams TE, Schonfeld SE. In vitro activity of chlorhexidine against enteric rods, pseudomonads and acinetobacter from human periodontitis. Oral Microbiol Immunol 1991;6:62-4.

16. Haapasalo $M$, Ranta $H$, Ranta KT. Facultative gram-negative enteric rods in persistent periapical infections. Acta Odontol Scand 1983;41:19-22.

17. Heling I. Steinberg D, Kenig S, Gavrilovich I, Sela MN, Friedman M Efficacy of a sustained-release device containing chlorhexidine and $\mathrm{Ca}(\mathrm{OH})_{2}$ in preventing secondary infection of dentinal tubules. Int Endod J 1992;25:20-4.

18. Siqueira JF, Jr., Uzeda M. Intracanal medicaments: evaluation of the antibacterial effects of chlorhexidine, metronidazole, and calcium hydroxide associated with three vehicles. J Endodon 1997;23:167-9.

19. Ohara PK, Torabinejad M, Kettering JD. Antibacterial effects of various endodontic irrigants on selected anaerobic bacteria. Endod Dent Traumatol 1993;9:95-100.

20. Siqueira JF, Jr., Batista MMD, Fraga RC, Uzeda M. Antibacterial effects of endodontic irrigants on black-pigmented gram-negative anaerobes and facultative bacteria. J Endodon 1998;24:414-6. 